\title{
Raw264.7 Cells Secrete Fibroblast Growth Stimulating Activity after Differentiation to Macrophages by Stimulation with Lipopolysaccharide
}

\author{
Jing-Yang Lai1 ${ }^{1}$, Chung-Li Shu1, Kazuhiro Morishita ${ }^{2}$, Tomonaga Ichikawa ${ }^{2}$, Yasuhisa Fukui ${ }^{*}$ \\ ${ }^{1}$ Institute of Cellular and System Medicine, National Health Research Institute, Miaoli County, Taiwan \\ ${ }^{2}$ Division of Tumor and Cellular Biochemistry, Department of Medical Sciences, Faculty of Medicine, University \\ of Miyazaki, Miyazaki, Japan \\ Email: "990412@nhri.org.tw
}

Received 27 June 2014; revised 25 July 2014; accepted 25 August 2014

Copyright (C) 2014 by authors and Scientific Research Publishing Inc.

This work is licensed under the Creative Commons Attribution International License (CC BY).

http://creativecommons.org/licenses/by/4.0/

cc) (i)

Open Access

\begin{abstract}
Raw264.7 cells are monocytic cells that can differentiate to activated macrophages after lipopolysaccharide (LPS) stimulation. Here, we analyzed the factors secreted by Raw264.7 cells in response to LPS. The culture media of LPS-treated Raw264.7 cells was able to stimulate growth in MEF1F2 and NIH3T3 mouse fibroblast cell lines. We identified five secreted and LPS-induced chemokines, CCL2, CCL5, CCL12, CxCL2, and CxCL10, by microarray analysis and tested their stimulatory activity. We used commercially available bacterially expressed proteins, and found only CCL12, CXCL2 and CXCL10 stimulated growth in MEF1F2 and NIH3T3 cells. The saturation density of the cells was also increased. They were not able to stimulate growth in v-Src transformed MEF1F2 or SWAP-70 transformed NIH3T3 cells. We examined signaling pathways activated by these three factors. We found that ERK and p38 MAP kinase were activated and were required for the activity to stimulate the cell growth. Other pathways including phosophatidylinositol-3 kinase (PI3K), NF $\kappa$ B pathways were not activated. These results suggest that Raw264.7 cells secretes growth stimulation factors for fibroblasts when differentiated to macrophages implicating that fast growth of them is related to inflamation although the reason is still unclear.
\end{abstract}

\section{Keywords}

Raw264.7 Cells, Chemokine, Fibroblasts, Macrophage

*Corresponding author.

How to cite this paper: Lai, J.-Y., Shu, C.-L., Morishita, K., Ichikawa, T. and Fukui, Y. (2014) Raw264.7 Cells Secrete Fibroblast Growth Stimulating Activity after Differentiation to Macrophages by Stimulation with Lipopolysaccharide. CellBio, 3, 87-95. http://dx.doi.org/10.4236/cellbio.2014.33009 


\section{Introduction}

Inflammation in vascular tissues is part of a complex biological response to harmful stimuli, such as pathogens, damaged cells, or irritants [1]. An early step during inflammation is the activation of macrophages, which perform several key tasks during non-specific and specific defense pathways of vertebrates. They function to phagocytose, or engulf and then digest, cellular debris and pathogens. Macrophages also stimulate lymphocytes and other immune cells to respond to pathogens. However, they may also participate by secreting chemokines that affect the environment.

Chemokines are a family of small molecular weight cytokines, or signaling proteins secreted by cells [2] [3]. Chemokines are classified according to their structural characteristics such as their small molecular size and the presence of four conserved cysteine residues. Some chemokines are considered pro-inflammatory. They can be induced during an immune response and help to recruit immune cells to the site of infection. Other chemokines are considered homeostatic and are involved in controlling the migration of cells during tissue maintenance and development. CCL2 is a small molecular weight cytokine that belongs to the CC chemokine family. CCL2 recruits monocytes, memory T cells, and dendritic cells to sites of inflammation produced by either tissue injury or infection [4] [5]. CCL2 can bind to and activate either CCR2 or CCR5 receptor. CCL5 is an 8 kDa protein classified as either a cytokine or chemokine that is chemotactic for T cells, eosinophils, and basophils. CCL5 plays an active role in recruiting leukocytes to inflammatory sites [6]. CCL5 can bind to CCR1, CCR3 or CCR5 receptor. CCL12, is a small molecular weight cytokine belonging to the CC chemokine family, and its activity has been described in mice. CCL12 specifically recruits eosinophils, monocytes and lymphocytes. This chemokine can be greatly induced in macrophages and is predominately found in lymph nodes and thymus under a normal condition [7]. The corresponding receptor for CCL12 is CCR2. C-x-C motif chemokine CxCL2 is a small molecular weight cytokine belonging to the $\mathrm{CxC}$ chemokine family that is also called macrophage inflammatory protein 2-alpha (MIP2-alpha), Growth-regulated protein beta (Gro-beta) and Gro oncogene-2 (Gro-2). This chemokine is secreted by monocytes and macrophages and is chemotactic for polymorphonuclear leukocytes and hematopoietic stem cells [8]-[10]. CxCL2 mobilizes cells by interacting with a cell surface chemokine receptor called CxCR2 [10].

CxCL10 is also a C-X-C motif chemokine with a molecular weight of $8.7 \mathrm{kDa}$ in humans [11] [12]. CXCL10 is a ligand for the CxCR3 receptor, and is secreted by monocytes, endothelial cells and fibroblasts in response to IFN- $\gamma$ [13]. CxCL10 activity is important in several processes including chemoattraction for monocytes/macrophages, T cells, NK cells, and dendritic cells, promotion of T cell adhesion to endothelial cells, antitumor activity, and inhibition of bone marrow colony formation and angiogenesis [14] [15].

Raw264.7 monocytic cells differentiate to form activated macrophages, which are polarized toward that of the M2 macrophage phenotype, upon lipopolysaccharide (LPS) stimulation. Many studies have focused on the function of macrophages during inflammation, and PDGF, EGF, and some other factors have been shown to be secreted for growth of fibroblasts but there is still a room to be seen about other factors. Also during wound and healing, macrophages secrete growth factors [16] [17]. In this paper, we show that Raw264.7 cells secrete cytokines as they differentiate to activated macrophage and discuss the potential functions of these factors.

\section{Materials and Methods}

\subsection{Cell Lines and Culture Conditions}

Raw264.7 and NIH3T3 cells were purchased from the Food Industry Research and Development Institute, Taiwan. NIH3T3/SWAP-70-590 cells were transformed with SWAP-70 as described before [18]. NIH3T3 related cells were cultured in high glucose DMEM supplemented with $200 \mathrm{mM}$ glutamine and $10 \%$ calf serum. Raw264.7 cells were cultured in low glucose DMEM supplemented with $4 \mathrm{mM}$ glutamine and 10\% fetal bovine serum. MEF1F2 cells are normal mouse embryonic fibroblasts (MEF) lacking the SWAP70 gene [19]. MEF1F2 cells are cultured in normal low glucose medium and can maintain a normal phenotype for more than 7 years. In contrast, wild type MEFs usually transform after several months of culture. SWAP-70(-)/SWAP70/v-Src-1 cells are v-Src transformed MEF1F2 cells as described previously [19].

\subsection{Preparation of Culture Media of Raw264.7 Cells}

To obtain culture supernatants of Raw264.7 cells, they were stimulated with $100 \mathrm{ng} / \mathrm{ml}$ LPS and cultured for 24 
hrs. The culture supernatant was collected. For the control culture supernatant, cells were cultured for 24 hrs and LPS was added just after harvesting the culture supernatant.

To test activated Raw264.7 cells continuously secrete the growth stimulating factors, confluent Raw264.7 cells were incubated with or without $100 \mathrm{ng} / \mathrm{ml}$ LPS and after 24 hours the culture supernatant was harvested. Then, new medium without LPS was added to the culture, incubated for 24 hours, medium was changed again, incubated for another $24 \mathrm{hrs}$, and the culture medium was harvested.

\subsection{Bacterially Expressed Chemokines, Antibodies, and Reagents Used in This Study}

Bacterially expressed chemokines, CCL2, CCL5, CCL12, CxCL2, and CxCL10 were purchased from R \& D system (Minneapolis, MN, USA). Anti-ERK, anti-phospho ERK, p38 MAP kinase, anti-phospho p38 MAP kinase, Akt, anti-Phospho Akt, anti-I $\kappa \mathrm{B}$, and anti-phosphoI $\kappa \mathrm{B}$ antibodies were purchased from Cell Signaling Co Ltd (Danvers, MA, USA). An ERK inhibitor, PD59089 and a p38 MAP kinase inhibitor, SB203580, were purchased from WAKO Co. Ltd (Tokyo, Japan).

\subsection{PCR Reaction and Western Blotting}

RNA extraction was performed using RNA extraction kit (Zymo Research, Irvine, CA, U.S.A.). Reverse transcriptase reaction was performed using the PrimeScript (Takara, Tokyo, Japan). PCR was done using ExTaq polymerase (Takara). Presence of chemokine receptors was analyzed by PCR using the following primers: ATGGAGATTTCAGATTTCACAGAAG and TCAGAAGCCAGCAGAGAGCTCATGTTC (CCR1); ATG GAAGACAATAATATGTTACC and TCACTTACTTTACAACCCAACCG (CCR2); GGCATTCAACACAG ATGA AATCAAG and CTAAAACACCACAGAGATTTCTTGC (CCR3); ATGGATTTTCAAGGGTCAGT TCCG and TCATGTTCTCCTGTGGATCGGGTATAG (CCR5); CAAAGATGGGAGAATTCAAGGTGG and CTTTAGAGGGTAGTAGAGGTGT (CxCR2); and ATGTACCTTGAGGTTAGTGAACG and TTACAAGC CCAGGTAGGAGGCC (CxCR3).

Cells were harvested after stimulation of the chemokines. Cells were lysed with a buffer containing $10 \mathrm{mM}$ Tris-HCl pH 7.5, $100 \mathrm{mM} \mathrm{NaCl,} 5 \mathrm{mM}$ EDTA, $1 \mathrm{mM}$ sodium vanadate, and $1 \mathrm{mM}$ PMSF. Aliquots of the samples were loaded on the SDS-PAGE and Western blotting was done as described before [20].

\subsection{Examination of Cell Growth}

Cells were plated at a density of $3 \times 10^{4}$ cells per dish in $3.5 \mathrm{~cm}$ dishes. To maintain growth factor activity, the media were changed every day. Number of cells in each dish were counted and expressed in graphs. To test effect of concentration of chemokines $1 \times 10^{5}$ cells were seeded and cultured for two days in the presence of various concentrations of chemokines.

\subsection{Microarray}

RNA was prepared from confluent cultures of MEF1F2, MEF1F2-SWAP-1, and MEF1F2-SWAB-7 cells. For microarray analysis, oligoarray type array (Agilent SurePrint G3 Mouse GE 8 x 60K) was used. Total RNA (0.2 mg) was labeled with Cy3-CTP using Agilent low input quick-Amp labeling kit. Hybridization was done by Agilent one-color microarray-based gene expression analysis low input quick-amp labeling kit v6.5 using $0.6 \mu \mathrm{g}$ of cRNA. Genes whose expression levels were increased two fold compared with control cells were selected with p-value cut off of 0.05 .

\section{Results and Discussion}

\subsection{Activated Raw264.7 Cells Secrete Factors That Stimulate Growth in Normal Fibroblasts}

Raw264.7 cells were stimulated with $100 \mathrm{ng} / \mathrm{ml}$ LPS and their culture medium was harvested after $24 \mathrm{~h}$. Subsequently, SWAP-70(-) and NIH3T3 cells were incubated overnight with the harvested media. We found that this treatment led to growth stimulation in fibroblasts, but the effects were not sustained for longer than $24 \mathrm{~h}$. We speculated that this was due to the potential instability of growth factors in the harvested medium. Indeed, daily replenishment of harvested media led to sustained growth stimulation of fibroblasts (Figure 1(a)). 


\subsection{The Secreted Growth-Stimulating Factors Are Chemokines}

Secreted factors from LPS-treated Raw264.7 cells maintained their growth stimulatory activity for several days (Figure 1(b)). These results suggested that the factors were continuously secreted and therefore, transcriptionally upregulated. Accordingly, we performed microarray analysis of LPS-stimulated Raw264.7 cells. We found that many genes were over-expressed after LPS treatment. The number of the genes expressed two folds or more of the control cells was 254 out of 28,853 genes. Among these, we selected secretable proteins containing signal peptides for secretion. They were chemokines, CCL2, CCL5, CCL12, CxCL2 and CxCL10. They increased 8.29, 22.5, 3.45, 11.07, 2.61 fold each compared with control cells. We suspected that these proteins stimulated the cell growth of the fibroblasts and tested the activities of commercially available proteins. Only CCL12, CxCL2 and CxCL10 exhibited the activities and CCL2 and CCL5 did not (Figure 2).

\subsection{Growth of Transformed Cells Is Not Affected by Secreted Chemokines}

We tested the effect of CCL12, CxCL2 and CxCL10 on transformed MEF1F2 or NIH3T3 cells. The cells grown in the presence of these chemokines showed fast growth compared to the control cells, suggesting that they stimulate cell growth. However, they exhibited contact inhibition at the higher cell densities, suggesting that the cells are not transformed (Figure 3(a) and Figure 3(b)). This higher saturation density was outstanding. Unlike normal cells, growth was not stimulated by these chemokines in transformed cells (Figure 4(a) and Figure $4(\mathrm{~b}))$.

\subsection{Expression of Chemokines Receptors in MEFs and NIH3T3 Cells}

To confirm that MEF1F2 and NIH3T3 cells expressed the receptors for these chemokines, we performed PCR. Bands were obtained using RNAs of MEF1F2 and NIH3T3 cells (Figure 5). These bands were cloned and sequenced. The results showed that these bands were indeed PCR products of CCR2, CCR3, CCR5, CxCR2, and CxCR3, which are the receptors for the secreted chemokines studied in this paper. Despite this, only a subset of chemokines was able to induce cell growth.

\subsection{Signaling of Cytokines That Stimulate Cell Growth of Fibroblasts}

We tested whether several signaling pathways which are widely studied are activated upon stimulation by these cytokines. As shown in Figure 6(a), ERK was clearly activated 5 to 10 min after stimulation. p38 MAP kinase

(a)

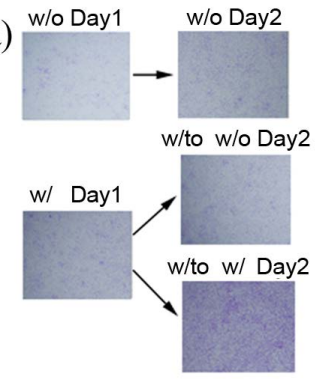

(b)

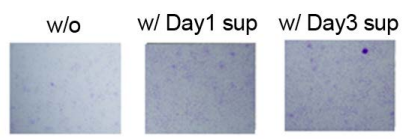

Figure 1. Daily replacement is required to maintain growth-stimulating activity of LPS-induced Raw264.7 culture media. (a) MEF1F2 cells were cultured with culture media of Raw264.7 cells. After cultivation with culture media of LPS-treated Raw264.7 cells for one day (w/Day1), the cell density of Raw264.7 cells was significantly higher than that of using LPS-untreated Raw264.7 cells (w/o Day1). Medium was replaced with culture media of LPS-treated Raw264.7 cells for 1 day and then replaced culture media from LPS-untreated (w/o Day2) or LPS-treated (w/Day2) culture media. Cells grew faster when cultured with media from LPS-treated Raw264.7 cells. (b) MEF1F2 was cultured with culture media of Raw264.7 cells stimulated with LPS (w/Day1 sup) or that obtained by further incubation without LPS stimulation for 72 hours (w/o Day3 sup). w/: culture supernatant of LPS-treated Raw264.7 cells; w/o: culture supernatant of LPS-untreated Raw264.7 cells. 
(a)
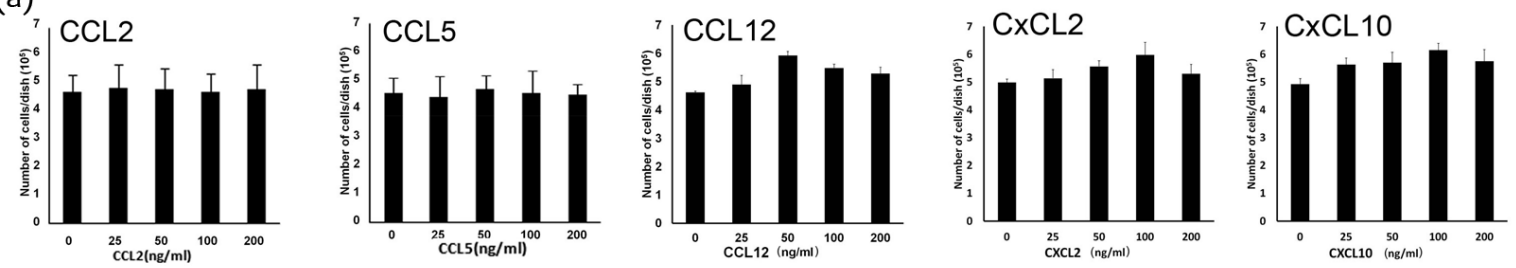

(b)
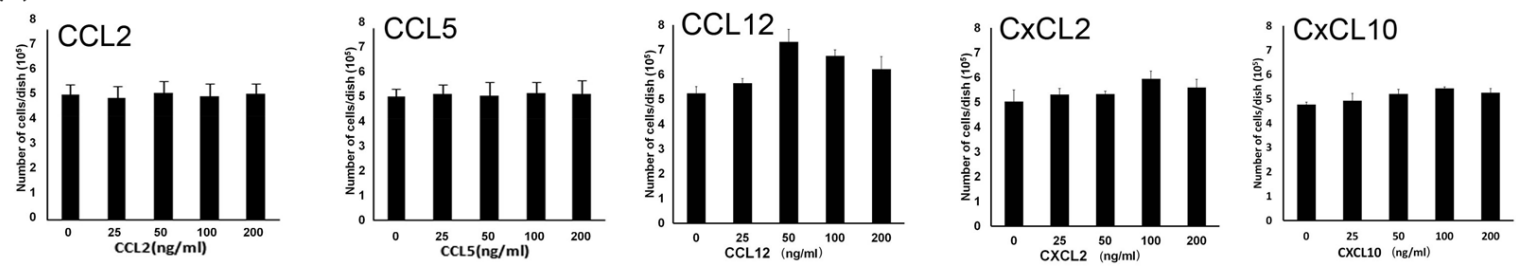

Figure 2. Concentration of chemokines required for fast cell growth. MEF1F2 (a) or NIT3T3 (b) cells were seeded at the density of $1 \times 10^{4}$ cells per $3.5 \mathrm{~cm}$ dishes. Various doses of CCL2, CCL5, CCL12, CxCL2, and CxCL10 were added to the cultures. The medium was changed to the ones containing the same concentration of chemokines on the following day. The numbers of the cells were counted $24 \mathrm{hrs}$ after the medium change. The results are the averages of three independent experiments.

(a)
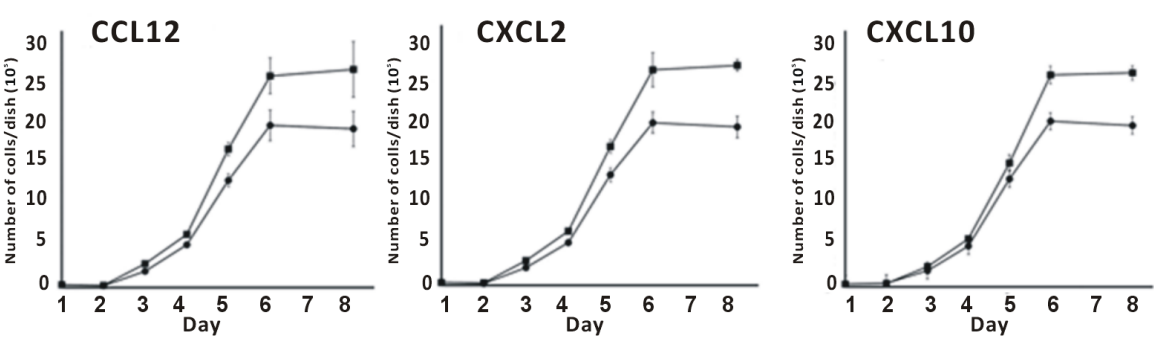

(b)
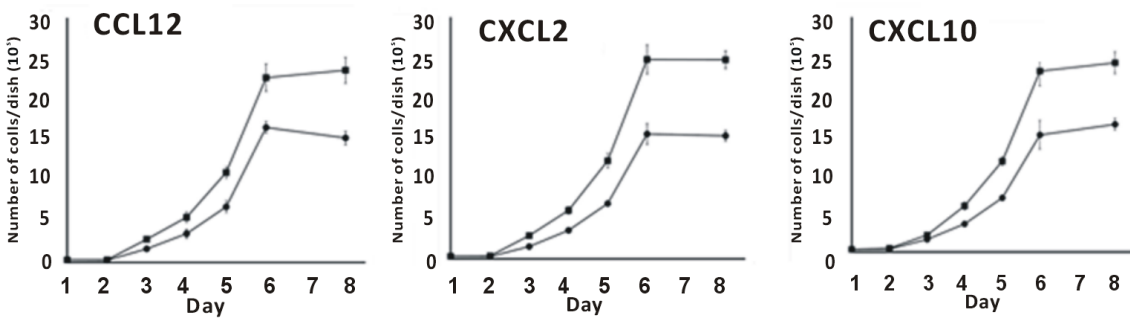

Figure 3. Growth curve of fibroblasts stimulated with culture media containing bacterially expressed chemokines. MEF1F2 (a) or NIH3T3 (b) cells were plated at the density of $3 \times 10^{4}$ cells/dish in $3.5 \mathrm{~cm}$ dishes. Commercially available chemokines (50 ng/ml for CCL12 and 100 $\mathrm{ng} / \mathrm{ml}$ for CxCL2 and CxCL10) were added to the cells. The medium was changed every day. The number of cells in dishes were counted and plotted on the graph. Closed circles indicate controls, while closed squares highlight the growth curve of chemokine-treated cells. Error bars represent standard deviation. The results are the averages of three independent experiments.

was also activated. However, Akt and $\mathrm{NF} \kappa \mathrm{B}$ monitered by phosphorylation of $\mathrm{I} \kappa \mathrm{B}$ remained inactivated. We also monitored some other signaling molecules such as PKC $\alpha$ but none of them were activated (data not shown).

To see which pathway is related to fast growth of the cells, we used inhibitors for the signaling pathways and test growth stimulation activities of the cytokines. As shown in Figure 6(b), PD59089, an inhibition of ERK, and SB203580, a p38 MAP kinase inhibitor, clearly inhibited growth stimulation, suggesting that these two pathways are necessary for stimulation of the cells to grow faster than the control cells. How these pathways 
(a)

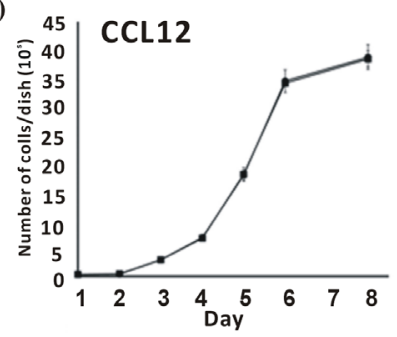

(b)

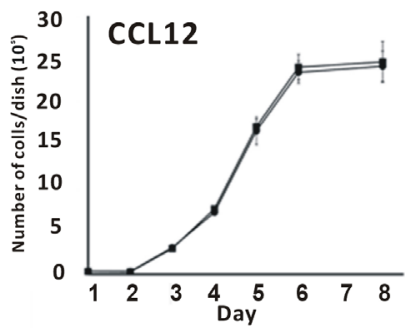

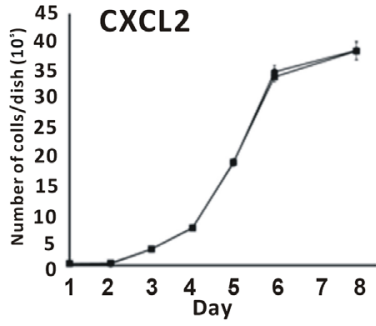
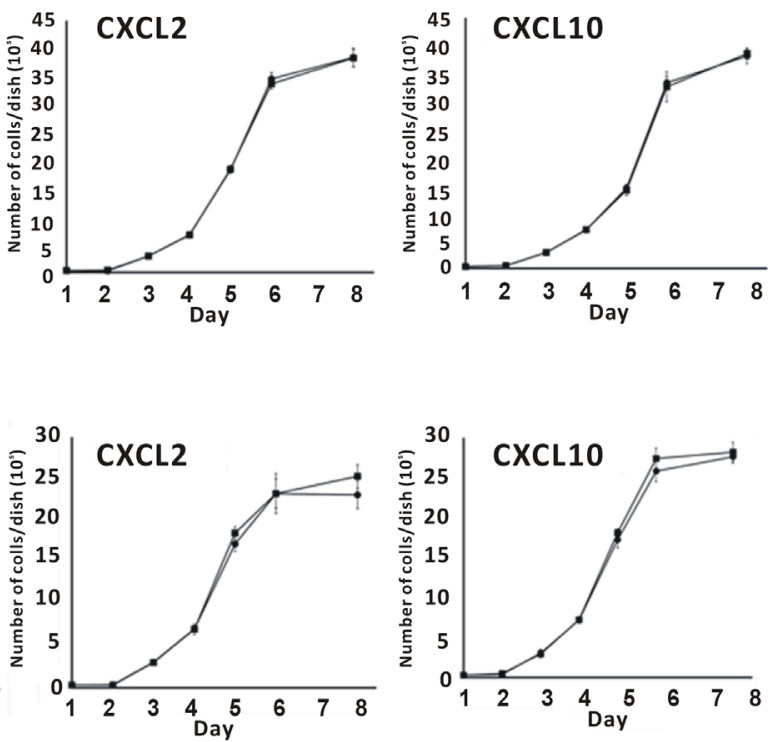

Figure 4. Growth of transformed fibroblasts is not stimulated by bacterially expressed chemokines. SWAP-70(-)/SWAP70/v-Src-1 (a) or NIH3T3/SWAP-70-590 (b) cells were plated at the density of $3 \times 10^{4}$ cells/dish in $3.5 \mathrm{~cm}$ dishes. Commercially available chemokines (50 ng/ml for CCL12 and $100 \mathrm{ng} / \mathrm{ml}$ for CxCL2 and CxCL10) were added to the cells. The medium was changed every day. The number of cells in dishes were counted and plotted on the graph. Closed circles indicate controls, while closed squares highlight the growth curve of chemokine-treated cells. Error bars represent standard deviation. The results are the averages of three independent experiments.

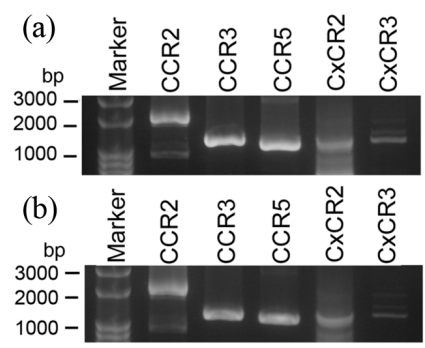

Figure 5. Expression of chemokine receptors. Expression of chemokine receptors in MEF1F2 (a) and NIH3T3 (b) cells was analyzed by PCR. The bands were cloned and sequenced to confirm the bands are really the signals of the chemokine receptors.

contribute to fast growth of the cells should be studied in the future.

Chemokines function as chemo-attractants during the process of inflammation. Moreover, they stimulate growth of some immune cells. However, their effects on the neighboring fibroblasts have not been fully appreciated. In this paper, we found that certain chemokines secreted from macrophages can stimulate growth of fibroblasts. The role of this activation is unclear, but it is possible that the growth of fibroblasts can support immune cell activity at the site of inflammation.

CCL12, CxCL2, and CxCL10 showed growth stimulation activity. To make sure that only CCL12, CxCL2, and CxCL10 have the activity, we cloned the genes for CCL2, CCL5, CCL12, CxCL2, and CxCL10 and expressed the proteins in 293T cells. Again CCL2 and CCL5 did not show the activity and other three showed significant activity, confirming the results of bacterially expressed protein.

The cells, which are stimulated with CCL12, CxCL2, and CxCL10 maintained contact inhibition activity, although the saturation cell number was bigger than that of the untreated cells. Therefore, the cells grow faster but they are not transformed. However it is possible that continuous activation of the cells might transform the cells. Further study is required to get the conclusion of this question. 
(a)

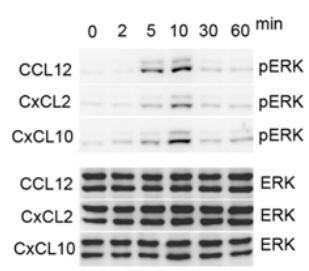

(e)

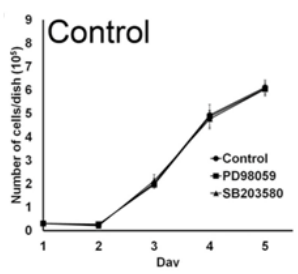

(f)

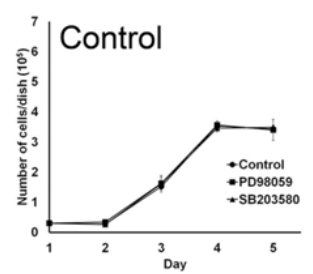

(b)

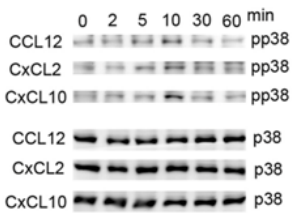

(c)

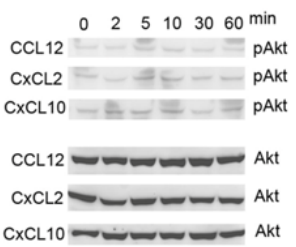

(d)
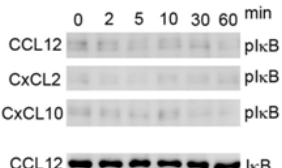

$\mathrm{CxCL} 2-0-2=0$

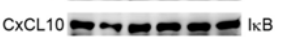

$\beta$-actin ーーーーーー
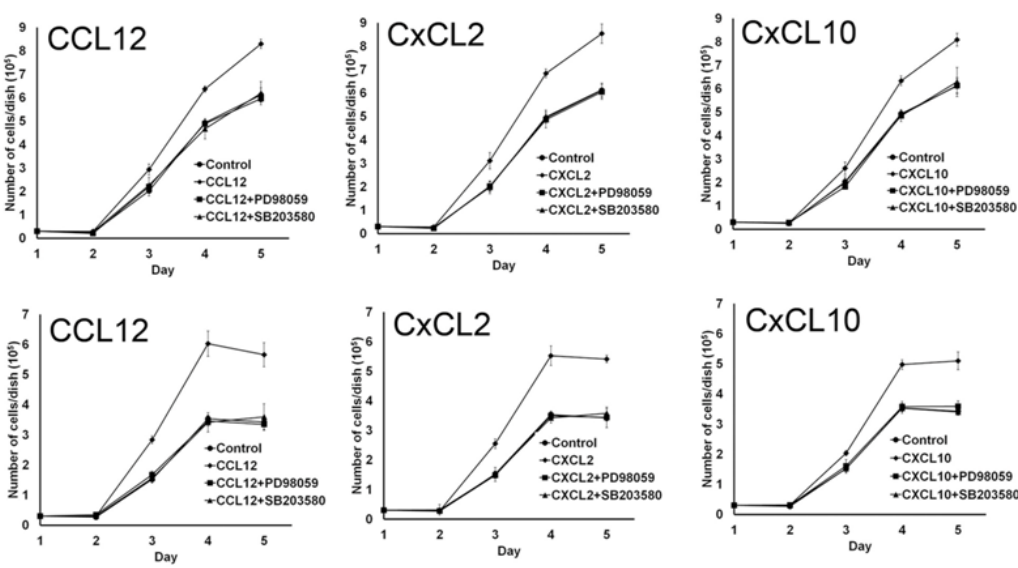

Figure 6. Signaling of chemokine stimulation and requirement of the signal for fast growth of the cells. MEF1F2 cells were stimulated with the chemokines shown in the figure (50 ng/ml for CCL12 and $100 \mathrm{ng} / \mathrm{ml}$ for CxCL2 and CxCL10). Cells were harvested at the time indicated in the figure. Activation of ERK (a), p38 MAP kinase (b), Akt (c), and NF $\kappa$ B (d) were monitored. (e) MEF1F2 cells were plated at the density of $3 \times 10^{4}$ cells/dish in $3.5 \mathrm{~cm}$ dishes. Commercially available chemokines $(50 \mathrm{ng} / \mathrm{ml}$ for CCL12 and $100 \mathrm{ng} / \mathrm{ml}$ for CxCL2 and CxCL10) were added. Also, an ERK inhibitor PD98059 (10 $\mu \mathrm{M})$ or a p38 MAP kinase inhibitor, SB203580 $(10 \mu \mathrm{M})$, was added in some dishes. The medium was changed every day. The number of cells in dishes were counted and plotted on the graph. (f) The same experiment as (e) was done using NIH 3 T3 cells. The symbols are shown in the figures. The results are the averages of three independent experiments.

The interplay between chemokines and their corresponding receptors is complex. We found that CCR2, CCR3, CCR5, CxCR2, and CxCR3 are expressed in MEFs and NIH3T3 cells, however the complex interplay of signaling networks downstream of these receptors have complicated the functional analysis of chemokines. We found that the MAP kinase and p38 MAP kinase pathways were important for the cells to grow fast, however Akt and $\mathrm{NF} \kappa \mathrm{B}$ were not. CCL12, CxCL2, and CxCL10 take different receptors however the signaling was very similar, suggesting that these receptors play a similar role for signal transduction. Here, we found that CCL2 and CCL12 elicit distinct biological responses, although they bind to the same receptor. Why CCL2 does not show growth stimulation activity is a mystery. It is possible that CCL12 reacts with unknown receptor which is required for cells growth or CCL2 reacts with another unknown receptor which inhibits stimulation of cell growth. For instance, activation of CCR5 might inhibit fast growth of the cells.

In this study we found that chemokines, CCL12, CxCL2, and CxCL10 can stimulate growth of fibroblasts. However, they have to be added every day maybe because of their instability. Therefore, Cell growth of normal fibroblasts will be stimulated only when chemokines are supplied by macrophages in vivo. For the fast growth of the cells, activation of the ERK and 38 MAP kinase pathways was required. However, cell growth of transformed cells was stimulated, and probably the ERK and the 38 MAP kinase pathways are already activated. Stimulation of growth of fibroblasts may be limited to very specific condition, which we do not know yet. It is interesting that there are appropriate concentrations of chemokines to stimulate the cell growth. This result may implicate that there is a fine regulation of growth of fibroblasts by macrophage. This may be an important finding to consider what is happening in vivo. Further study is required to understand the meaning of the observation we made in this paper.

\section{Acknowledgements}

This paper is supported by a grant from the National Health Research Institute: 01A1-CSPP04-014 and from the 
National Science Council Taiwan: 101-2300-B-400-015.

\section{References}

[1] Ferrero-Miliani, L., Nielsen, O.H., Andersen, P.S. and Girardin, S.E. (2007) Chronic Inflammation: Importance of NOD2 and NALP3 in Interleukin-1beta Generation. Chronic Inflammation: Importance of NOD2 and NALP3 in Interleukin-1beta Generation. Clinical \& Experimental Immunology, 147, 227-235.

[2] Comerford, I. and McColl, S.R. (2011) Mini-Review Series: Focus on Chemokines. Mini-Review Series: Focus on Chemokines. Immunology and Cell Biology, 89, 183-184. http://dx.doi.org/10.1038/icb.2010.164

[3] Allen, S.J., Crown, S.E. and Handel, T.M. (2007) Chemokine: Receptor Structure, Interactions, and Antagonism. Chemokine: Receptor Structure, Interactions, and Antagonism. Annual Review of Immunology, 25, 787-820. http://dx.doi.org/10.1146/annurev.immunol.24.021605.090529

[4] Carr, M.W., Roth, S.J., Luther, E., Rose, S.S. and Springer, T.A. (1994) Monocyte Chemoattractant Protein 1 Acts as a T-Lymphocyte Chemoattractant. Proceedings of the National Academy of Sciences of the United States of America, 91, 3652-3656. http://dx.doi.org/10.1073/pnas.91.9.3652

[5] Xu, L.L., Warren, M.K., Rose, W.L., Gong, W. and Wang, J.M. (1996) Human Recombinant Monocyte Chemotactic Protein and Other C-C Chemokines Bind and Induce Directional Migration of Dendritic Cells in Vitro. Journal of Leukocyte Biology, 60, 365-371.

[6] Maghazachi, A.A., Al-Aoukaty, A. and Schall, T.J. (1996) CC Chemokines Induce the Generation of Killer Cells from CD56+ Cells. CC Chemokines Induce the Generation of Killer Cells from CD56+ Cells. European Journal of Immunology, 26, 315-319. http://dx.doi.org/10.1002/eji.1830260207

[7] Jia, G.Q., Gonzalo, J.A., Lloyd, C., Kremer, L., Lu, L., Martinez, A.C., Wershil, B.K. and Gutierrez-Ramos, J.C. (1996) Distinct Expression and Function of the Novel Mouse Chemokine Monocyte Chemotactic Protein-5 in Lung Allergic Inflammation. The Journal of Experimental Medicine, 184, 1939-1951. http://dx.doi.org/10.1084/jem.184.5.1939

[8] Wolpe, S.D., Sherry, B., Juers, D., Davatelis, G., Yurt, R.W. and Cerami, A. (1989) Identification and Characterization of Macrophage Inflammatory Protein 2. Identification and Characterization of Macrophage Inflammatory Protein 2. Proceedings of the National Academy of Sciences of the United States of America, 86, 612-616. http://dx.doi.org/10.1073/pnas.86.2.612

[9] Iida, N. and Grotendorst, G.R. (1990) Cloning and Sequencing of a New Gro Transcript from Activated Human Monocytes: Expression in Leukocytes and Wound Tissue. Molecular and Cellular Biology, 10, 5596-5599.

[10] Pelus, L.M. and Fukuda, S. (2006) Peripheral Blood Stem Cell Mobilization: The CXCR2 Ligand GRObeta Rapidly Mobilizes Hematopoietic Stem Cells with Enhanced Engraftment Properties. Experimental Hematology, 34, 1010-1020. http://dx.doi.org/10.1016/j.exphem.2006.04.004

[11] Luster, A.D., Unkeless, J.C. and Ravetch, J.V. (1985) Gamma-Interferon Transcriptionally Regulates an Early-Response Gene Containing Homology to Platelet Proteins. Nature, 315, 672-676. http://dx.doi.org/10.1038/315672a0

[12] Luster, A.D., Jhanwar, S.C., Chaganti, R.S., Kersey, J.H. and Ravetch, J.V. (1987) Interferon-Inducible Gene Maps to a Chromosomal Band Associated with a $(4 ; 11)$ Translocation in Acute Leukemia Cells. Proceedings of the National Academy of Sciences of the United States of America, 84, 2868-2871. http://dx.doi.org/10.1073/pnas.84.9.2868

[13] Sarafi, M.N., Garcia-Zepeda, E.A., MacLean, J.A., Charo, I.F. and Luster, A.D. (1997) Murine Monocyte Chemoattractant Protein (MCP)-5: A Novel CC Chemokine That Is a Structural and Functional Homologue of Human MCP-1. The Journal of Experimental Medicine, 185, 99-109. http://dx.doi.org/10.1073/pnas.84.9.2868

[14] Dufour, J.H., Dziejman, M., Liu, M.T., Leung, J.H., Lane, T.E. and Luster, A.D. (2002) IFN-Gamma-Inducible Protein 10 (IP-10; CXCL10)-Deficient Mice Reveal a Role for IP-10 in Effector T Cell Generation and Trafficking. The Journal of Immunology, 168, 3195-3204. http://dx.doi.org/10.4049/jimmunol.168.7.3195

[15] Angiolillo, A.L., Sgadari, C., Taub, D.D., Liao, F., Farber, J.M., Maheshwari, S., Kleinman, H.K., Reaman, G.H. and Tosato, G. (1995) Human Interferon-Inducible Protein 10 Is a Potent Inhibitor of Angiogenesis in Vivo. The Journal of Experimental Medicine, 182, 155-162. http://dx.doi.org/10.4049/jimmunol.168.7.3195

[16] Rappolee, D.A., Mark, D., Banda, M.J. and Werb, Z. (1988) Wound Macrophages Express TGF-Alpha and Other Growth Factors in Vivo: Analysis by mRNA Phenotyping. Science, 241, 708-712. http://dx.doi.org/10.4049/jimmunol.168.7.3195

[17] Pierce, G.F., Mustoe, T.A., Senior, R.M., Reed, J., Griffin, G.L., Thomason, A. and Deuel, T.F. (1988) In Vivo Incisional Wound Healing Augmented by Platelet-Derived Growth Factor and Recombinant C-Sis Gene Homodimeric Proteins. The Journal of Experimental Medicine, 167, 974-987. http://dx.doi.org/10.4049/jimmunol.168.7.3195

[18] Shu, C.L., Yang, L.J., Su, L.C., Chuu, C.P. and Fukui, Y. (2013) SWAP-70: A New Type of Oncogene. PLoS ONE, 8, e59245. http://dx.doi.org/10.4049/jimmunol.168.7.3195 
[19] Fukui, Y., Tanaka, T., Tachikawa, H. and Ihara, S. (2007) SWAP-70 Is Required for Oncogenic Transformation by V-Src in Mouse Embryo Fibroblasts. Biochemical and Biophysical Research Communications, 356, 512-516. http://dx.doi.org/10.1016/j.bbrc.2007.03.011

[20] Oka, T., Ihara, S. and Fukui, Y. (2007) Cooperation of DEF6 with Activated Rac in Regulating Cell Morphology. The Journal of Biological Chemistry, 282, 2011-2018. http://dx.doi.org/10.1074/jbc.M605153200 
Scientific Research Publishing (SCIRP) is one of the largest Open Access journal publishers. It is currently publishing more than 200 open access, online, peer-reviewed journals covering a wide range of academic disciplines. SCIRP serves the worldwide academic communities and contributes to the progress and application of science with its publication.

Other selected journals from SCIRP are listed as below. Submit your manuscript to us via either submit@scirp.org or Online Submission Portal.
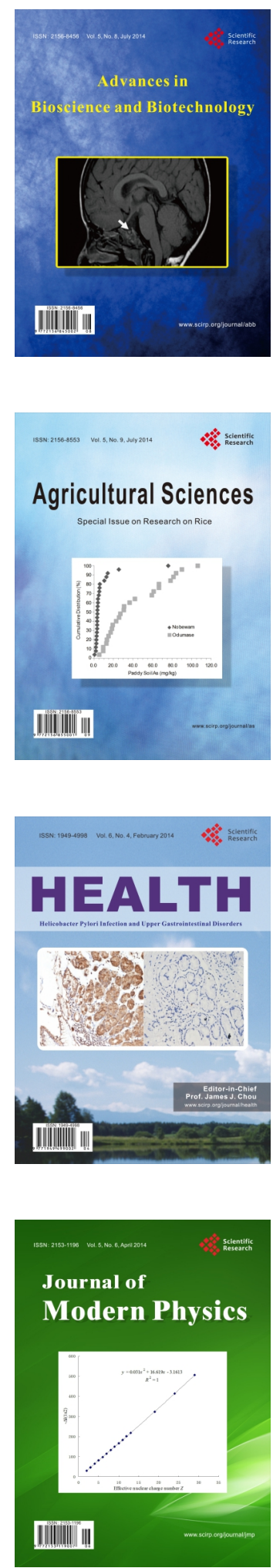
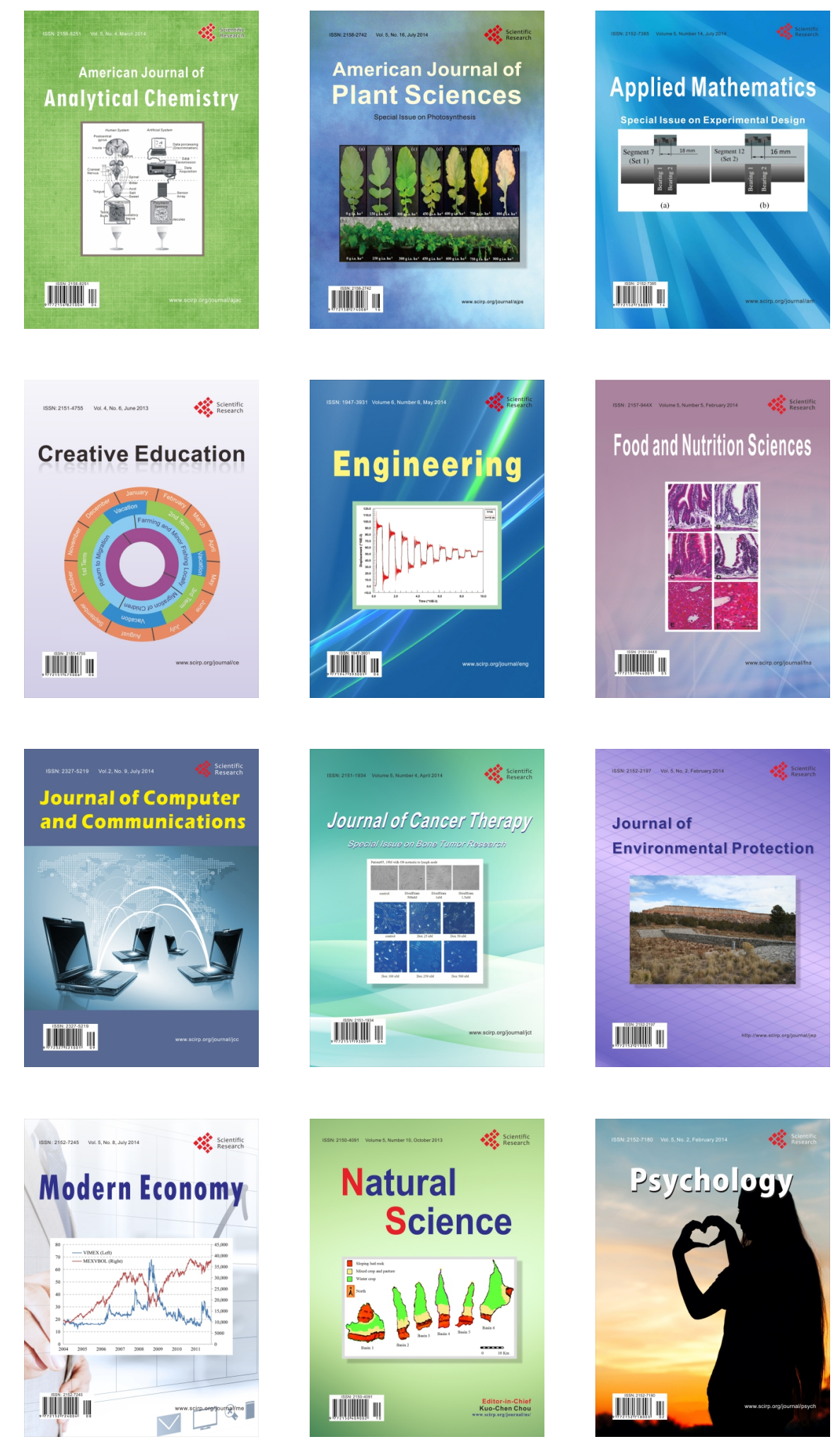